\title{
FAKTOR-FAKTOR YANG MEMPENGARUHI TINGKAT KEPUASAN HUNIAN PERUMAHAN BERSUBSIDI DI KOTA MALANG
}

\author{
Agus Inter Arma Caritas ${ }^{* 1}$, Wisnumurti ${ }^{2}$, Agus Suharyanto ${ }^{3}$ \\ ${ }^{1}$ Mahasiswa / Magister / Teknik Sipil / Universitas Brawijaya \\ ${ }^{2}$ Dosen / Teknik Sipil / Universitas Brawijaya \\ ${ }^{3}$ Dosen / Teknik Sipil / Universitas Brawijaya \\ Korespondensi : caritasarma@gmail.com
}

\begin{abstract}
The city of Malang is one of the largest cities in East Java will not be separated from the problem of housing needs. However, there are still many people who do not have homes, especially for low-income people. In meeting the needs of homes, low-income residents find it difficult to have cash in house and limited costs. Therefore, the government provides a program to facilitate the residents in meeting the needs of the house that is with the program Housing Financing Liquidity Facility (FLPP). This study aims to increase the role of stakeholders in building subsidized housing as measured by the level of satisfaction of residents in subsidized housing in Malang. Analyzes for the support used include descriptive analysis to explain the occupants' satisfaction for each housing sample. And the method used is the importance-performance analysis (IPA), Customer Satisfaction Index (CSI) and Regression. After the results of data processing, obtained the results of the level of customer satisfaction assessing the performance of subsidized housing developers in Malang included into the category either, Index Performance) totaling 67.02\%. And where variable of location factor, building quality factor, and completeness factor of facility and infrastructure have positive influence to satisfaction of subsidized housing resident in Malang City.
\end{abstract}

Keywords : Importance Performance Analysis (IPA), Regression, Resident Satisfaction, Subsidized Housing.

\section{PENDAHULUAN}

Perumahan merupakan salah satu masalah yang akan dihadapi oleh kota-kota besar. Kota Malang adalah salah satu kota terbesar di Jawa Timur tidak akan terlepas dari masalah kebutuhan perumahan. Secara umum kota sebagai pusat permukiman mempunyai peran penting dalam memberi pelayanan di berbagai bidang kehidupan bagi penduduknya dan daerah sekitarnya. Kota merupakan pusat pelayanan jasa, produksi, distribusi serta menjadi pintu gerbang atau simpul transportasi bagi daerah permukiman dan produksi sekitarnya. Kota adalah suatu wilayah geografis tempat bermukim sejumlah penduduk dengan tingkat kepadatan yang relatif tinggi, dengan kegiatan utamanya di sektor nonpertanian (Bappenas, 1996). Pemerintah melalui Kementerian Pekerjaan Umum dan Perumahan Rakyat (PUPR) akan memberikan insentif bagi para pengembang yang membangun perumahan dengan pola hunian berimbang dalam mendorong program Satu Juta Rumah. Selain itu, mempermudah perizinan pembangunan rumah MBR atau rumah bersubsidi di daerah.Perlunya dilakukan penelitian ini dikarenakan tidak semua pelaksanaan perumahan bersubsidi berjalan dengan baik. Ini dapat dilihat dari kondisi eksisting perumahan bersubsidi yang tidak semua rumah dihuni oleh pemiliknya sendiri tetapi ada juga yang disewakan, kosong dan disita oleh pihak bank. Oleh Karena itu, upaya meningkatkan peran stakeholder sangat penting untuk membantu menyelesaikan permasalahan perumahan subsidi. Stakeholder disini adalah pengembang, pemerintah, dan penghuni. Sehingga sangat pentinganya peneliti untuk mengukur kepuasan penghuni perumahan subsidi. Kepuasan penghuni perumahan subsidi ditentukan oleh terpenuhinya persyaratan lokasi, kualitas 
bangunan, dan terutama dukungan sarana dan prasarana. Melalui penelitian ini peneliti ingin mengkaji lebih dalam tentang faktor - faktor yang akan diberikan kepada stakeholder untuk diperbaiki agar penghuni puas pada perumahan bersubsidi dengan lokasi berbeda yang ada di Kota Malang. Sasaran Penelitian sebagai berikut :

1. Menganalisis tingkat kepuasan penghuni pada perumahan bersubsidi di Kota Malang untuk memberikan faktor-faktor yang akan diperbaiki stakeholder agar penghuni puas.

2. Menganalisis pengaruh pengaruh faktor lokasi, faktor kualitas bangunan, dan kelengkapan sarana dan prasarana terhadap kepuasan penghuni perumahan bersubsidi di Kota Malang.

3. Mengetahui faktor yang dominan dalam tingkat kepuasan penghuni perumahan bersubsidi di Kota Malang.

\section{TINJAUAN PUSTAKA}

\section{Menurut Mastutie 103-110, Agustus}

2013, Perumahan bagi masyarakat berpenghasilan menengah ke bawah atau yang diistilahkan dengan rumah „Subsidieditujukan dalam rangka memenuhi kebutuhan mereka akan tempat tinggal. Dikatakan Subsidi karena proses pengadaannya disubsidi oleh pemerintah. Bentuk subsidi yang diberikan berupa : subsidi meringankan kredit dan subsidi menambah dana pembangunan atau perbaikan rumah. Kredit subsidi ini diatur tersendiri oleh Pemerintah, sehingga tidak setiap masyarakat yang mengajukan kredit dapat diberikan fasilitas ini. Secara umum batasan yang ditetapkan oleh pemerintah dalam memberikan subsidi adalah penghasilan pemohon dan maksimum kredit yang diberikan.

Berdasarkan Gasperz (1997), faktor-faktor penilaian konsumen pada perumahan sederhana ini adalah kualitas produk berupa struktur komponen dan bahan bangunan, faktor lokasi, desain bangunan, serta sarana dan prasarana dalam lingkungan perumahan.

\subsection{Faktor Lokasi}

Menurut SNI 03-1733-2004 tentang tata cara perencanaan lingkungan perumahan di perkotaan, Lokasi lingkungan perumahan harus memenuhi ketentuan sebagai berikut:

a) Lokasi perumahan harus sesuai dengan rencana peruntukan lahan yang diatur dalam
Rencana Tata Ruang Wilayah (RTRW) setempat atau dokumen perencanaan lainnya yang ditetapkan dengan Peraturan Daerah setempat.

b) Lokasi perencanaan perumahan harus berada pada lahan yang jelas status kepemilikannya, dan memenuhi persyaratan administratif, teknis dan ekologis.

c) Keterpaduan antara tatanan kegiatan dan alam di sekelilingnya, dengan mempertimbangkan jenis, masa tumbuh dan usia yang dicapai, serta pengaruhnya terhadap lingkungan, bagi tumbuhan yang ada dan mungkin tumbuh di kawasan yang dimaksud.

\subsection{Faktor kualitas bangunan}

Menurut Keputusan Menteri

Permukiman Dan Prasarana Wilayah Nomor: 403/Kpts/M/2002 Tentang Pedoman Teknis Pembangunan Rumah Sederhana Sehat (Rs Sehat) Menteri Permukiman Dan Prasarana Wilayah bahwa Ketentuan Rumah Sederhana Sehat (RSH) meliputi :

1. Kebutuhan Minimal Penampilan dan Ruang (luar-dalam)

2. Kebutuhan Kesehatan dan Kenyamanan Aspek-aspek tersebut merupakan dasar atau kaidah perencanaan rumah sehat dan nyaman.

a) Pencahayaan

b) Penghawaan

c) Suhu udara dan kelembaban

3. Kebutuhan Minimal Keamanan dan Keselamatan

\subsection{Faktor Kelengkapan Sarana dan Prasarana}

Menurut SNI 03-1733-2004 tentang tata cara perencanaan lingkungan perumahan di perkotaan, Lokasi lingkungan perumahan harus memenuhi ketentuan sebagai berikut:

Jenis sarana

Yang termasuk dalam sarana pemerintahan dan pelayanan umum adalah:

a) kantor-kantor pelayanan / administrasi pemerintahan dan administrasi kependudukan;

b) kantor pelayanan utilitas umum dan jasa; seperti layanan air bersih (PAM), listrik (PLN), telepon, dan pos; serta 
d) pos-pos pelayanan keamanan dan keselamatan; seperti pos keamanan dan pos pemadam kebakaran.

Prasarana lingkungan perumahan yang harus disiapkan meliputi kelengkapan lingkungan yang berupa:
a. Jaringan drainase
b. Jaringan air bersih
c. Jaringan air limbah
d. Jaringan persampahan
e. Jaringan listrik
f. Jaringan telepon
g. Jaringan transportasi local

\section{METODE PENELITIAN}

Penelitian ini dilaksanakan pada perumahan subsidi di Kota Malang. Berikut lokasi penelitian masing-masing perumahan :

a.Perumahan Kenikir Permai termasuk wilayah di kelurahan Bumiayu, kecamatan Kedungkandang, kota Malang.

b.Perumahan Kecipir Permai termasuk wilayah di kelurahan Bumiayu, kecamatan Kedungkandang, kota Malang.

c.Perumahan Griya 8 Permai termasuk wilayah di kelurahan Bumiayu, kecamatan Kedungkandang, kota Malang.

d.Perumahan Akasia Permai termasuk wilayah di kelurahan Gadang, kecamatan Sukun, kota Malang.

e.Perumahan Griya Buring Permai termasuk wilayah di kelurahan Buring, kecamatan Kedungkandang, kota Malang.

f.Perumahan Bulan Terang Utama termasuk wilayah di kelurahan Madyopuro, kecamatan Kedungkandang, kota Malang.

Dasar peneliti mengambil perumahanperumahan tersebut, dikarenakan setelah survei yang telah dilaksanakan perumahan yang telah disebutkan diatas memiliki kesamaan atau homogen dan termasuk perumahan bersubsidi yang telah dilaksanakan oleh pengembang di Kota Malang.

Jenis data yang dibutuhkan dalam penelitian ini adalah data primer dan data sekunder. Data primer diambil dari responden, yaitu penghuni rumah di perumahan Kenikir Permai, perumahan Kecipir Permai perumahan Griya 8 Permai, perumahan Akasia Permai, perumahan Griya Buring Permai dan Perumahan Bulan Terang Utama, dengan menggunakan kuisioner (angket) tertutup dengan pertanyaan yang sudah disediakan dengan asumsi bahwa responden memahami maksud setiap pernyataan yang disampaikan. Kuesioner dibagikan oleh peneliti langsung ke responden dengan harapan responden menjawab dengan sungguh-sungguh.

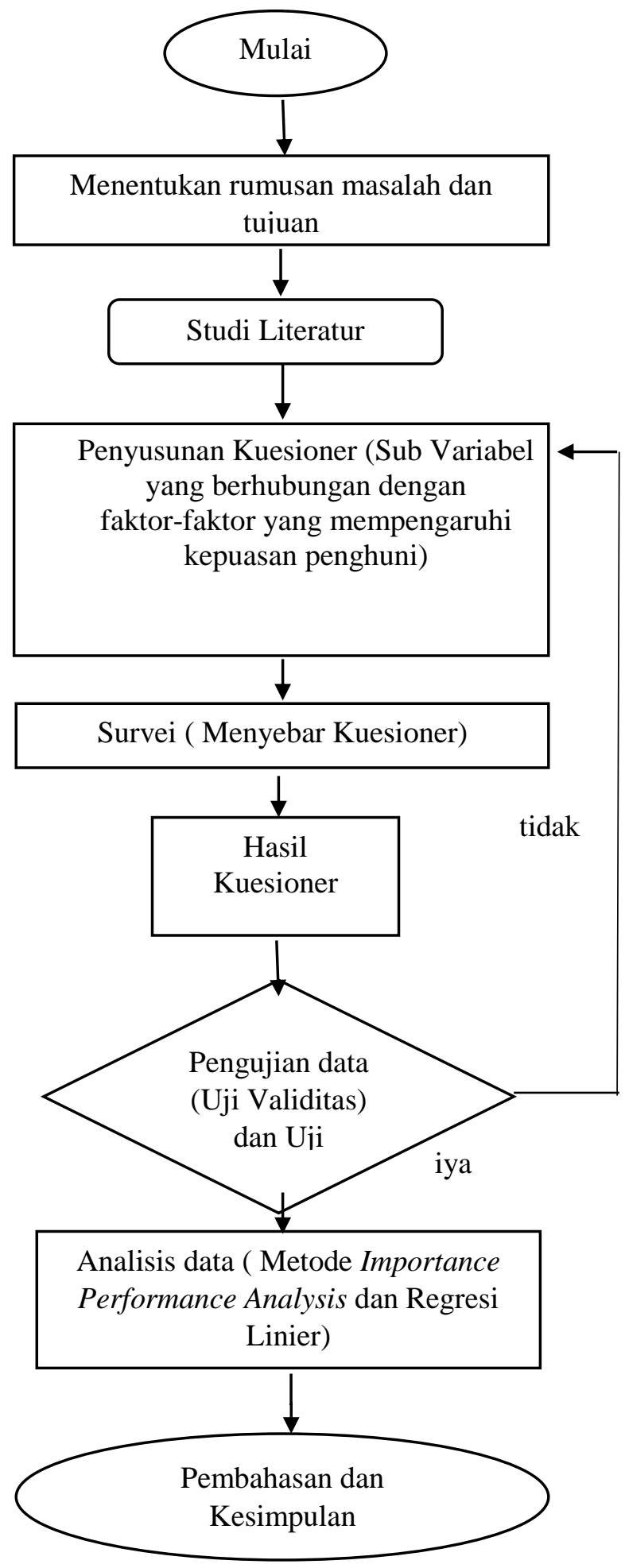

Gambar 1. Diagram alir penelitian 
Data sekunder adalah data berbentuk naskah tertulis atau dokumen yang telah diolah lebih lanjut dan disajikan oleh pihak-pihak tertentu dan berfungsi sebagai referensi data primer (Riskiyah, 2015). Data sekunder diperoleh dari pengembang perumahan yaitu PT. Bunga Properti Malang dan PT. Bulan Terang Utama.

Data yang diperoleh kemudian dianalisis menggunakan metode-metode berikut:

\subsection{Analisa deskriptif}

Hasil pengamatan atau dari obeservasi dan data sekunder akan disajikan dengan analis statistik deskriptif. Pada statistik deskriptif ini, akan dikemukakan cara-cara penyajian data, dengan tabel distribusi frekuensi dan gambar hasil olah data kuisioner.

\subsection{Importance Performance Analysis (IPA)}

Importance Performance Analysis (IPA) secara konsep merupakan suatu model multiatribut. Teknik ini mengidentifikasi kekuatan dan kelemahan penawaran pasar dengan menggunakan dua kriteria yaitu kepentingan relatif atribut dan kepuasan konsumen.

Langkah pertama untuk analisis kuadran adalah menghitung rata-rata penilaian kepentingan dan kinerja setiap produk layanan dengan rumus:

$$
\overline{X \imath}=\frac{\sum_{\mathrm{i}=l}^{k} X i}{n}
$$

Di mana:

$$
\begin{aligned}
& \overline{X l}=\text { Bobot rata-rata tingkat kepuasan ke-i } \\
& \overline{Y l}=\text { Bobot rata-rata tingkat kepentingan ke-i } \\
& \mathrm{N}=\text { Jumlah responden }
\end{aligned}
$$

Langkah selanjutnya adalah menghitung ratarata tingkat kepentingan dan kepuasan untuk keseluruhan produk layanan dengan rumus:

$$
\begin{aligned}
& \overline{\overline{X \imath}}=\frac{\sum_{i=1}^{k} \overline{X_{l}}}{n} \\
& \overline{\overline{Y_{l}}}=\frac{\sum_{i=1}^{k} \overline{Y_{l}}}{n}
\end{aligned}
$$

Di mana:

$$
\begin{aligned}
& \overline{X_{l}}=\text { Nilai rata-rata kepuasan atribut } \\
& \overline{Y l}=\text { Nilai rata-rata kepentingan atribut }
\end{aligned}
$$

$\mathrm{n}=$ Jumlah produk layanan

Nilai $\overline{\bar{X}}$ ini memotong tegak lurus pada sumbu horizontal, yakni sumbu yang mencerminkan kinerja produk layanan (X) sedangkan $\overline{\bar{Y}}$ nilai memotong tegak lurus pada sumbu vertikal, yakni sumbu yang mencerminkan kepentingan produk layanan (Y). setelah diperoleh bobot kinerja dan kepentingan produk layanan serta nilai rata-rata kinerja dan kepentingan produk layanan, kemudian nilai-nilai tersebut diplotkan ke dalam diagram kartesius.

Selanjutnya dilakukan analisis CSI (Customer Satisfaction Index) digunakan untuk mengetahui tingkat kepuasan penghuni secara menyeluruh dengan melihat tingkat kepentingan dari produk-produk layanan.

\subsection{Rergresi linier berganda}

Analisis ini digunakan untuk menguji variabel bebas secara bersama-sama terhadap variabel terikat. Analisis ini digunakan untuk menguji hipotesis, yaitu faktor lokasi, faktor kualitas bangunan, dan kelengkapan sarana dan prasarana berpengaruh positif terhadap kepuasan penghuni perumahan subsidi di Kota Malang.

\section{HASIL DAN PEMBAHASAN}

\subsection{Metode Importance Performance Analysis (IPA)}

Untuk pertanyaan pada tingkat kepentingan dan tingkat kepuasan menggunakan skala likert. Setiap jawaban dihubungkan dengan bentuk pernyataan atau dukungan sikap yang diungkapkan dengan kata-kata sebagai berikut : pernyataan positif ; sangat puas (5), Puas (4), Cukup Puas (3), Kurang Puas (2), dan Tidak Puas (1). Sehingga dari pertanyaan positif pada kuesioner berdasarkan fakta pada perumahan subsidi di Kota Malang, jika sesuai dengan standar maka nilai yang ideal untuk rata-rata setiap atribut adalah $4-5$, Karena hasil nilai rata-rata ideal untuk nilai tersebut adalah dari puas sampai dengan sangat puas yang akan menunjukkan bahwa kepuasan penghuni perumahan subsidi kota malang dalam kategori puas.

Berdasarkan hasil perhitungan rata-rata tingkat kepentingan dan tingkat kepuasan, selanjutnya akan dibuat dalam bentuk diagram Importance Performance Analysis (IPA) dengan meletakkan skor tingkat kepuasan 


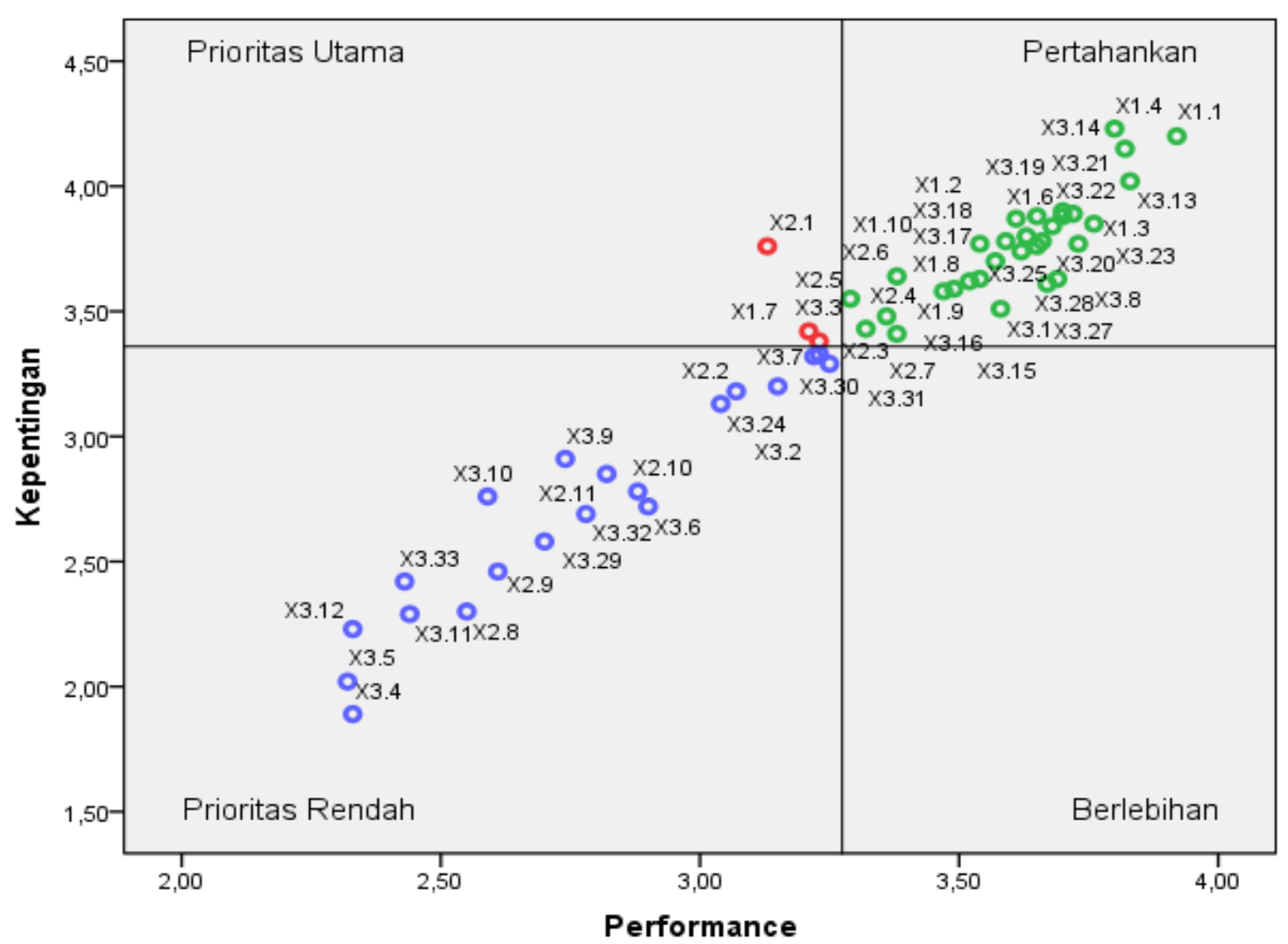

Gambar 2. Diagram Importance Performance Analysis (IPA)

(Performance) sebagai sumbu mendatar (X) dan tingkat kepentingan (Importance) sebagai sumbu tegak (Y). Dengan demikian akan dapat dikelompokkan atribut kedalam setiap kuadran Importance Performance Analysis (IPA), bentuk diagram dapat dilihat pada Gambar 2.

Berdasarkan diagram Importance Performance Analysis (IPA) diatas, maka atribut-atribut yang mempengaruhi kepuasan konsumen perumahan subsidi di Kota Malang dapat dikelompokkan pada masing-masing kuadran yang diambil nilai rata-rata paling tinggi dan paling rendah pada setiap variabel. Atribut-atribut yang termasuk dalam kuadran prioritas utama yaitu atribut yang dianggap penting tetapi kepuasannya masih dianggap kurang, sehingga perlu perhatian dan peningkatan oleh developer dapat dilihat pada Tabel 1.

Atribut-atribut yang termasuk dalam kategori pertahankan prestasi dan harus tetap dipertahankan kinerjanya, karena sudah sesuai dengan keinginan stakeholder yaitu atribut yang dianggap penting dan kepuasannya dapat dilihat pada Tabel 2.

Tabel 1. Atribut yang termasuk dalam kategori prioritas utama

\begin{tabular}{c|c|c}
\hline Variabel & $\begin{array}{c}\text { Kode } \\
\text { Atribut }\end{array}$ & Pertanyaan \\
\hline Lokasi & X1.7 & $\begin{array}{c}\text { Lokasi } \\
\text { perumahan } \\
\text { mudah } \\
\text { memperoleh } \\
\text { transportasi } \\
\text { umum }\end{array}$ \\
Kualitas & $\mathrm{X} 2.1$ & $\begin{array}{c}\text { Kondisi rumah } \\
\text { sesuai dengan } \\
\text { spesifikasi yang } \\
\text { ada di brosur. }\end{array}$ \\
\hline Sarana & $\mathrm{X} 3.3$ & $\begin{array}{c}\text { Tersedianya } \\
\text { tempat untuk } \\
\text { ronda malam pada } \\
\text { perumahan. }\end{array}$ \\
\hline
\end{tabular}


Tabel 2. Atribut yang termasuk dalam pertahankan prestasi

\begin{tabular}{|c|c|c|}
\hline Variabel & $\begin{array}{l}\text { Kode } \\
\text { Atribut }\end{array}$ & Pertanyaan \\
\hline Lokasi & X1.1 & $\begin{array}{c}\text { Lokasi } \\
\text { Perumahan } \\
\text { bebas dari } \\
\text { buangan limbah }\end{array}$ \\
\hline Variabel & $\begin{array}{c}\text { Kode } \\
\text { Atribut }\end{array}$ & Pertanyaan \\
\hline Lokasi & X1.9 & $\begin{array}{l}\text { Jarak lokasi } \\
\text { perumahan } \\
\pm 2 \mathrm{~km} \\
\text { dekat dengan } \\
\text { pemakaman }\end{array}$ \\
\hline $\begin{array}{c}\text { Kualitas } \\
\text { Bangunan }\end{array}$ & X2.6 & $\begin{array}{c}\text { Lubang } \\
\text { penghawaan } \\
\text { keluar tidak } \\
\text { mengganggu } \\
\text { kenyamanan } \\
\text { bangunan } \\
\text { disekitarnya } \\
\end{array}$ \\
\hline & $\mathrm{X} 2.5$ & $\begin{array}{c}\text { Udara yang } \\
\text { masuk } \\
\text { rumah tidak } \\
\text { berasal dari } \\
\text { asap dapur atau } \\
\text { bau kamar mandi } \\
\text { /WC. } \\
\end{array}$ \\
\hline \multirow[t]{2}{*}{$\begin{array}{c}\text { Sarana } \\
\text { dan } \\
\text { Prasarana }\end{array}$} & X3.14 & $\begin{array}{c}\text { Air yang } \\
\text { digunakan } \\
\text { PDAM di } \\
\text { perumahan cukup } \\
\text { untuk } \\
\text { kebutuhan } \\
\text { sehari-hari }\end{array}$ \\
\hline & X3.31 & $\begin{array}{c}\text { Ketersedian } \\
\text { jalan pada } \\
\text { perumahan } \\
\text { yang } \\
\text { memadai } \\
\text { sehingga } \\
\text { mudah untuk } \\
\text { berpapasan } 2 \\
\text { mobil pribadi }\end{array}$ \\
\hline
\end{tabular}

Atribut-atribut yang termasuk dalam kategori prioritas rendah dan harus tetap diperbaiki kinerjanya, karena tidak sesuai dengan keinginan stakeholder yaitu atribut yang dianggap kurang penting dan kurang kepuasannya dapat dilihat pada Tabel 3. Hasil perhitungan Customer Satisfaction Index dapat dilihat pada Tabel 4.

Tabel 3. Atribut yang termasuk dalam prioritas rendah

\begin{tabular}{c|c|c}
\hline Variabel & $\begin{array}{c}\text { Kode } \\
\text { Atribut }\end{array}$ & Pertanyaan \\
\hline $\begin{array}{c}\text { Kualitas } \\
\text { Bangunan }\end{array}$ & X2.2 & $\begin{array}{c}\text { Tata ruang } \\
\text { sesuai/layak } \\
\text { dengan keinginan } \\
\text { pemilik. }\end{array}$ \\
\cline { 2 - 3 } & X2.8 & $\begin{array}{c}\text { Kondisi rumah } \\
\text { terbebas dari } \\
\text { kerusakan pada } \\
\text { dinding rumah }\end{array}$ \\
\hline $\begin{array}{c}\text { Sarana } \\
\text { Panarana }\end{array}$ & $\mathrm{X} 3.7$ & $\begin{array}{c}\text { Jarak perumahan } \\
\pm 2 \text { km dengan } \\
\text { apotik. }\end{array}$ \\
\cline { 2 - 3 } & $\mathrm{X} 3.4$ & $\begin{array}{c}\text { Tersedianya pos } \\
\text { pemadam } \\
\text { kebakaran pada } \\
\text { perumahan. }\end{array}$ \\
\hline
\end{tabular}

Tabel 4. CSI (Customer Satisfaction Index)

\begin{tabular}{|c|c|c|c|c|}
\hline \multirow{2}{*}{$\begin{array}{l}\text { Kode } \\
\text { Atribut }\end{array}$} & \multicolumn{2}{|c|}{$\bar{Y}$} & \multicolumn{2}{|c|}{$\bar{X}$} \\
\hline & Min & Max & Min & Max \\
\hline $\mathrm{X} 1$ & 3.42 & 4.23 & 3.21 & 3.92 \\
\hline $\mathrm{X} 2$ & 2.30 & 3.38 & 2.55 & 3.38 \\
\hline X3 & 1.89 & 4.15 & 2.32 & 3.83 \\
\hline Total & \multicolumn{2}{|c|}{181.38} & \multicolumn{2}{|c|}{176.80} \\
\hline \multirow{2}{*}{$\begin{array}{l}\text { Kode } \\
\text { Atribut }\end{array}$} & \multicolumn{2}{|c|}{$\begin{array}{c}\mathrm{WFm} \\
\left(\bar{Y} / \sum \mathrm{Y}^{*} 100\right)\end{array}$} & \multicolumn{2}{|c|}{$\begin{array}{c}\text { WSm } \\
(\bar{X} * \mathrm{WFm})\end{array}$} \\
\hline & Min & Max & Min & Max \\
\hline $\mathrm{X} 1$ & 1.89 & 2.33 & 6.06 & 9.07 \\
\hline $\mathrm{X} 2$ & 1.27 & 2.07 & 3.23 & 6.80 \\
\hline $\mathrm{X} 3$ & 1.04 & 2.29 & 2.43 & 8.73 \\
\hline Total & \multicolumn{2}{|c|}{100.00} & \multicolumn{2}{|c|}{335.09} \\
\hline
\end{tabular}

Berdasarkan perhitungan CSI (Customer Satisfaction Index) dapat diketahui bahwa Index Performance perumahan subsidi di Kota Malang adalah sebesar $67,02 \%$, nilai tersebut masuk dalam kriteria baik atau puas. Hal ini 
menunjukan tingkat kepuasan penghuni perumahan subsidi di Kota Malang baik.

\subsection{Analisis regresi linier berganda}

Tabel 4. Ringkasan hasil uji regresi liner berganda X1, X2 dan X3 terhadap Y

\begin{tabular}{l|l}
\hline Variabel & Koefisien \\
\hline $\mathrm{X} 1$ & 0,140 \\
\hline $\mathrm{X} 2$ & 0,212 \\
\hline $\mathrm{X} 3$ & 0,484 \\
\hline Konstanta & 67,763 \\
\hline Rhitung & 0,705 \\
\hline $\mathrm{R}^{2}$ & 0,497 \\
\hline
\end{tabular}

Dari perhitungan dengan menggunakan program Statistical Package for the Social Sciences (SPSS) versi 16.0 for windows didapatkan hasil besarnya konstanta dan koefisien pada Tabel 4, sehingga persamaan regresi linier gandanya sebagai berikut :

$$
\begin{aligned}
\mathrm{Y}= & \mathrm{a}+\mathrm{b} 1 \mathrm{X} 1+\mathrm{b} 2 \mathrm{X} 2+\mathrm{b} 3 \mathrm{X} 3 \\
= & 67,763+0,140 \mathrm{X} 1+0,212 \mathrm{X} 2 \\
& +0,484 \mathrm{X} 3
\end{aligned}
$$

Dari persamaan di atas dapat diketahui bahwa nilai koefisien X1 sebesar 0,140 bernilai positif yang berarti pengaruh dari $\mathrm{X} 1$ terhadap Y menunjukkan bahwa semakin besar kinerja developer perumahan dalam faktor lokasi akan meningkatkan kepuasan penghuni perumahan bersubsidi, nilai koefisien X2 sebesar 0,212 bernilai positif yang berarti pengaruh dari X2 terhadap Y menunjukkan bahwa semakin besar kinerja developer perumahan dalam faktor kualitas bangunan akan meningkatkan kepuasan penghuni perumahan bersubsidi, dan nilai koefisien X3 sebesar 0,484 bernilai positif yang berarti pengaruh dari X3 terhadap Y menunjukkan bahwa semakin besar kinerja developer perumahan dalam faktor kelengkapan sarana dan prasarana akan meningkatkan kepuasan penghuni perumahan bersubsidi.

Berdasarkan hasil analisis data dengan menggunakan program Statistical Package for the Social Sciences (SPSS) versi 16.0 for windows menunjukan $\mathrm{r}^{2}$ sebesar 0,497 . Hal ini menunjukkan bahwa variabel faktor lokasi (X1), faktor kualitas bangunan (X2), dan kelengkapan sarana dan prasarana (X3) memiliki kontribusi pengaruh terhadap kepuasan penghuni perumahan subsidi sebesar $49,7 \%$ sedangkan $51,3 \%$ ditentukan oleh variabel lain yang tidak diteliti seperti kualitas pelayanan atau jasa, harga rumah, kemudahan mendapatkan pinjaman, dan desain bangunan. Peneliti hanya membahas permasalahan pelaksanaan pembangunan perumahan bersubsidi di Kota Malang seperti faktor lokasi, faktor kualitas bangunan, dan kelengkapan sarana dan prasarana, sehingga untuk variable lain yang tidak diteliti bisa menjadi masukan untuk penelitian selanjutnya.

\subsection{Hasil uji dominan}

Tabel 5. Ringkasan hasil regresi secara parsial $\mathrm{X} 1, \mathrm{X} 2, \mathrm{X} 3$ dengan $\mathrm{Y}$

\begin{tabular}{c|c|c|l}
\hline No & Variabel & $\beta$ & Pengaruh \\
\hline 1 & $\mathrm{X} 1$ & 0,428 & Signifikan \\
\hline 2 & $\mathrm{X} 2$ & 0,539 & Signifikan \\
\hline 3 & $\mathrm{X} 3$ & 0,668 & Signifikan \\
\hline
\end{tabular}

Berdasarkan hasil dari tabel diatas, dapat dilihat bahwa terdapat variabel X3 (Kelengkapan Sarana dan Prasarana) merupakan variabel yang memiliki koefisien standarisasi $\beta$ paling besar, yaitu sebesar 0,668 . Hal ini menunjukkan bahwa variabel $Y$ (Kepuasan) lebih banyak dipengaruhi oleh variabel X3 (Kelengkapan Sarana dan Prasarana). Koefisien yang dimiliki oleh variabel X3 bertanda positif yang berarti jika terjadi peningkatan pada $\mathrm{X} 3$ maka terjadi peningkatan pada variabel $\mathrm{Y}$ dan sebaliknya jika terjadi penurunan pada variabel X3 maka terjadi penurunan pada variabel $\mathrm{Y}$.

\section{KESIMPULAN DAN SARAN}

\subsection{Kesimpulan}

1. Penghuni perumahan bersubsidi di Kota Malang telah merasa puas, Karena tingkat kepuasan konsumen menilai kinerja pengembang perumahan subsidi di Kota Malang termasuk kedalam kategori baik, dengan perolehan IP (Index Performance) secara keseluruhan sebesar 67,02\%.

2. Dari hasil analisis regresi linier ganda diperoleh hasil nilai koefisien regresi $(\beta)$ 
yang bernilai positif dimana variabel faktor lokasi, faktor kualitas bangunan, dan faktor kelengkapan sarana dan prasarana mempunyai pengaruh yang signifikan terhadap kepuasan penghuni perumahan subsidi di Kota Malang.

3. Hasil analisis regresi linier sederhana diperoleh hasil uji parsial dimana variabel faktor lokasi, faktor kualitas bangunan, dan faktor kelengkapan sarana dan prasarana yang mempunyai pengaruh paling besar terhadap kepuasan penghuni perumahan subsidi di Kota Malang adalah faktor kelengkapan sarana dan prasarana dengan nilai Koefisien Regresi $\beta$ paling besar, yaitu sebesar 0,668.

\subsection{Saran}

Berdasarkan kesimpulan yang telah diuraikan diatas maka dapat diberikan beberapa saran sebagai berikut :

\section{Bagi Pengembang}

Dalam penelitian ini diharapkan pengembang dapat melakukan peningkatan kinerja pada atribut-atribut yang dinilai penghuni penting dan yang akan memberikan kepuasan kepada penghuni perumahan subsidi.

2. Bagi Pemerintah

Terbentuknya kerja sama yang baik antara pengembang dengan pemerintah untuk meningkatkan kinerja pengembang terutama pada perumahan subsidi, agar pemerintah benar-benar bisa membantu dan memberi konstribusi dengan serius pengembang yang sedang melaksanakan pembangunan perumahan subsidi, sehingga perumahan subsidi tersebut layak dan.khususnya memberikan kepuasan terutama kepada masyarakat berpenghasilan rendah.

3. Bagi Penghuni

Penghuni memiliki konstribusi sangat besar pada perumahan subsidi, sehingga penghuni sebagai konsumen yang menilai kinerja pengembang seharusnya memberikan konstribusi kepada pengembang untuk meningkatkan atribut-atribut yang dianggap penting dan puas oleh penghuni pada perumahan subsidi tersebut.

4. Bagi Peneliti

Bagi penelitian selanjutnya disarankan untuk melakukan penelitian dengan ruang lingkup yang lebih luas dan diharapkan dapat mempertimbangkan faktor-faktor lain yang memiliki pengaruh terhadap kepuasan penghuni rumah bersubsidi. Banyak variabel bebas lain yang dapat mempengaruhi kepuasan penghuni, maka perlu indikatorindikator lain dari fakta yang terjadi program perumahan subsidi pemerintah untuk mengungkap variabel-variabel penelitian secara maksimal dalam penelitian ini.

\section{DAFTAR PUSTAKA}

[1] Badan Perencanaan Pembangunan Nasional. (1996). Pembangunan Perkotaan Dan Perdesaan, Perumahan Dan Permukiman. Jakarta: BAPPENAS.

[2] Jocom, J. (2015). Analisis Kepuasan Penghuni Perumahan Griya Paniki Indah Manado. Jurnal Ilmiah Media Engineering. Vol.5 No1 : 305 -314.

[3] Keputusan Menteri Permukiman Dan Prasarana Wilayah. (2002). Pedoman Teknis Pembangunan Rumah Sederhana Sehat (Rs Sehat).

Http://Www.Academia.Edu/5225567/Kepu tusan_Menteri_Permukiman_Dan_Prasaran a_Wilayah_Nomor_403_KPTS_M_2002_ Tentang_Pedoman_Teknis_Pembangunan Rumah_Sederhana_Sehat_Rs_Sehat. (Diakses 11 Agustus 2016).

[4] Kwanda, T. (2003). Analisis Kepuasan Penghuni Rumah Sederhana Tipe 36 Di Kawasan Sidoarjo Berdasarkan Faktor Kualitas Bagunan, Lokasi, Desain, Sarana Dan Prasarana. Dimensi Teknik Arsitektur. Vol. 31 , No. $2: 124: 132$.

[5] Mastutie, F. (2013). Model Penataan Jalan Di Perumahan „Subsidie“ Bagi Masyarakat Berpenghasilan Menengah Ke Bawah Pada Area Berkontur Melalui Pendekatan Arsitektur Lingkungan Dan Perilaku. Sabua. Vol.5, No.2: 103-110.

[6] Riskiyah, I. (2015). Analisis Kinerja Developer Terhadap Kepuasan Penghuni Perumahan Di Kota Malang. Jurnal Rekayasa Sipil. Volume 9, No.02 : 115-120.

[7] Standar Nasional Indonesia. (2004). Tata cara perencanaan lingkungan perumahan di perkotaan.

http://webcache.googleusercontent.com/sea rch?q=cache:FKAcykx8WDEJ:www.pu.go .id/uploads/services/infopublik2012022010 1311.pdf $+\& \mathrm{~cd}=1 \& \mathrm{hl}=\mathrm{id} \& \mathrm{ct}=\mathrm{clnk} \& \mathrm{gl}=\mathrm{id}$. (Diakses 15 Agustus 2016). 